\title{
Relationship between linear and nonlinear dynamics of heart rate and impairment of lung function in COPD patients
}

This article was published in the following Dove Press journal:

International Journal of COPD

17 August 2015

Number of times this article has been viewed

\author{
Adriana Mazzuco' \\ Wladimir Musetti \\ Medeiros ${ }^{2}$ \\ Milena Pelosi Rizk Sperling' \\ Aline Soares de Souza ${ }^{2}$ \\ Maria Clara Noman \\ Alencar $^{2}$ \\ Flávio Ferlin Arbex ${ }^{2}$ \\ José Alberto Neder ${ }^{2,3}$ \\ Ross Arena ${ }^{4}$ \\ Audrey Borghi-Silva' \\ 'Cardiopulmonary Physiotherapy \\ Laboratory, Federal University of \\ São Carlos, São Carlos, ${ }^{2}$ Pulmonary \\ Function and Clinical Exercise \\ Physiology Unit, Respiratory Division, \\ Department of Medicine, Federal \\ University of São Paulo, São Paulo, \\ Brazil; ${ }^{3}$ Laboratory of Clinical Exercise \\ Physiology, Division of Respiratory \\ and Critical Care Medicine, \\ Department of Medicine, Queen's \\ University, Kingston, ON, Canada; \\ ${ }^{4}$ Department of Physical Therapy and \\ Integrative Physiology Laboratory, \\ College of Applied Health Sciences, \\ University of Illinois Chicago, Chicago, \\ IL, USA
}

Correspondence: Audrey Borghi-Silva Cardiopulmonary Physiotherapy Laboratory, Federal University of São Carlos, Rodovia Washington Luís, km 235, Bairro Monjolinho, CEP I3565-905 São Carlos, SP, Brazil

Tel +55 I6 335। 8952

Email audrey@ufscar.br
Background: In chronic obstructive pulmonary disease (COPD), functional and structural impairment of lung function can negatively impact heart rate variability (HRV); however, it is unknown if static lung volumes and lung diffusion capacity negatively impacts HRV responses. We investigated whether impairment of static lung volumes and lung diffusion capacity could be related to HRV indices in patients with moderate to severe COPD.

Methods: Sixteen sedentary males with COPD were enrolled in this study. Resting blood gases, static lung volumes, and lung diffusion capacity for carbon monoxide $\left(\mathrm{DL}_{\mathrm{CO}}\right)$ were measured. The RR interval (RRi) was registered in the supine, standing, and seated positions (10 minutes each) and during 4 minutes of a respiratory sinus arrhythmia maneuver (M-RSA). Delta changes ( $\Delta$ supine-standing and $\Delta$ supine-M-RSA) of the standard deviation of normal RRi, low frequency (LF, normalized units [nu]) and high frequency (HF [nu]), SD1, SD2, alpha1, alpha2, and approximate entropy (ApEn) indices were calculated.

Results: HF, LF, SD1, SD2, and alpha1 deltas significantly correlated with forced expiratory volume in 1 second, $\mathrm{DL}_{\mathrm{CO}}$, airway resistance, residual volume, inspiratory capacity/total lung capacity ratio, and residual volume/total lung capacity ratio. Significant and moderate associations were also observed between $\mathrm{LF} / \mathrm{HF}$ ratio versus total gas volume $(\%), r=0.53 ; \mathrm{LF} / \mathrm{HF}$ ratio versus residual volume, $\%, r=0.52$; and HF versus total gas volume $(\%), r=-0.53(P<0.05)$. Linear regression analysis revealed that $\triangle \mathrm{RRi}$ supine-M-RSA was independently related to $\mathrm{DL}_{\mathrm{CO}}\left(r=-0.77, r^{2}=0.43, P<0.05\right)$.

Conclusion: Responses of HRV indices were more prominent during M-RSA in moderate to severe COPD. Moreover, greater lung function impairment was related to poorer heart rate dynamics. Finally, impaired lung diffusion capacity was related to an altered parasympathetic response in these patients.

Keywords: lung diffusion capacity, static lung volumes, rest hyperinflation, COPD, heart rate variability, cardiac autonomic nervous system

\section{Introduction}

Chronic obstructive pulmonary disease (COPD) is a complex disorder with diverse pathophysiological manifestations ${ }^{1}$ and the fourth leading cause of death throughout the world. ${ }^{2}$ Respiratory symptoms and impaired lung function, such as reductions in forced expiratory volume in 1 second $\left(\mathrm{FEV}_{1}\right)$, are well described predictors of coronary artery disease, ventricular arrhythmias, and cardiovascular mortality. ${ }^{3-6}$ Moreover, COPD patients present with a distinct autonomic imbalance, highlighted by abnormally diminished variations in heart rate.?

It seems that autonomic nervous system control in patients with COPD is influenced by variability at saturation level; hence, responses to sympathetic and parasympathetic 
stimuli are reduced. ${ }^{7}$ In fact, it has been previously described that excitatory modulation of the sinoatrial node as well as respiratory modulation are attenuated; this latter phenomenon is likely due to an increased in residual volume (RV). ${ }^{8}$ Also, impaired cardiac autonomic control is associated with inspiratory muscle weakness $^{9}$ and diminished heart rate variability (HRV), the latter being observed during a respiratory sinus arrhythmia maneuver (M-RSA), which is characterized as a parasympathetic stimuli. This response may be associated with changes in both lung compliance and lung stretch reflex responses in patients with cardiopulmonary disease ${ }^{10}$ and in healthy humans. ${ }^{11}$ Moreover, COPD causes neurohumoral activation, as evidenced by marked peripheral sympathetic activation (using microneurography of the peroneal nerve) and reduced baroreflex sensitivity. ${ }^{12}$

On the one hand, lung function tests are widely used to assess the efficacy of treatments in COPD patients and measures such as inspiratory capacity (IC) provide an important understanding of common symptoms such as dyspnea. ${ }^{1}$ Assessment techniques such as whole body plethysmography yield valuable information related to heterogeneous alterations occurring in patients with COPD that cannot be properly assessed by simple spirometry. ${ }^{13}$ Casanova et al, ${ }^{14}$ Zaman et al, ${ }^{15}$ and Albuquerque et $\mathrm{al}^{16}$ have argued that the IC/total lung capacity (TLC) ratio constitutes an important predictor of mortality, exacerbations, and maximal exercise capacity. Moreover, measurement of transfer factor provides additional prognostic information. ${ }^{17}$ On the other hand, there is still conflicting information related to the correlation between pulmonary function test variables and HRV indices in COPD patients. For example, Camillo et al ${ }^{18}$ did not demonstrate a correlation between resting HRV and disease severity (evaluated by simple spirometry), while another pilot study demonstrated that COPD patients with moderate and severe disease had abnormal cardiac autonomic modulation, which was related to the degree of lung function impairment. ${ }^{19}$

Thus, the objective of this study was to investigate whether impairment of lung function, especially in those variables obtained from static lung volumes (SLV) and diffusion capacity of the lung for carbon monoxide $\left(\mathrm{DL}_{\mathrm{CO}}\right)$, would be related to linear and non-linear HRV indices in patients with moderate to severe COPD. We hypothesized that higher levels of COPD disease severity would be related to more pronounced cardiac autonomic impairment.

\section{Subjects and methods Subjects}

Sixteen sedentary males with smoking-related $\mathrm{COPD}^{2}$ were enrolled in this observational, cross-sectional clinical study. All patients were evaluated in a specialized outpatient clinic by the same pneumologist and optimally treated before initiation of the study (Table 1). All patients presented with a clinical and spirometric diagnosis of COPD $\left(\mathrm{FEV}_{1} /\right.$ forced vital capacity $<0.7$ and post-bronchodilator $\mathrm{FEV}_{1}<80 \%$ predicted) at stages II, III, or IV. ${ }^{2}$ All subjects also reported suffering from chronic dyspnea (modified Medical Research Council scale score). No decompensation episodes occurred in any enrolled subject for at least 1 month prior to study initiation, and no subjects had participated in a regular physical exercise program for at least 6 months prior to study initiation. The exclusion criteria included long-term oxygen therapy, type 1 or non-controlled type 2 diabetes mellitus or peripheral vascular disease, the presence of neurological conditions that would preclude participation in the required protocol, uncontrolled hypertension, other concomitant respiratory diseases, current alcoholism, use of theophylline, and a history of cardiac arrhythmias or potential electrocardiogram alterations. The study was approved by the medical ethics committee of São Paulo Hospital, São Paulo, Brazil, and all subjects were informed about the study objectives, experimental procedures, and potential risks. All subjects gave written informed consent before study initiation.

\section{Outcome measurements}

Patients underwent the study assessments on an outpatient basis. The primary outcome was the relationship between parasympathetic HRV indices and both air trapping and reduced diffusion capacity. Secondary outcome measures included HRV responses during postural changes.

\section{Protocol}

All patients underwent a comprehensive evaluation, performed during 2 days: clinical evaluation by a pneumologist and physiotherapist, followed by lung function tests (resting blood gases, spirometry, $\mathrm{SLV}, \mathrm{DL}_{\mathrm{CO}}$, and maximal inspiratory and expiratory pressures) and Doppler echocardiography, and HRV data collection (supine, stand, sitting, and M-RSA, in this sequence).

\section{Measurements}

All subjects were evaluated at the same time of day (in order to avoid differences in response due to circadian rhythm) and were instructed to abstain from caffeinated and alcoholic beverages and not to perform exercise on the day before data collection.

\section{Lung function}

Spirometry, gas transfer, and SLV were measured (1085 Elite $\mathrm{D}^{\mathrm{TM}}$, Medical Graphics Corporation, St Paul, MN, USA) 
according to American Thoracic Society/European Respiratory Society guidelines. ${ }^{20-22}$ Reference values were previously described. ${ }^{23-25}$ Measurement of maximal inspiratory and expiratory pressures (1085 Elite D) was performed from the RV and TLC, respectively. ${ }^{26}$ Resting blood gases were obtained by samples from the radial artery, following standard procedures. ${ }^{27}$

Table I Baseline patient characteristics

\begin{tabular}{|c|c|}
\hline Clinical data & COPD patients $(n=16)$ \\
\hline \multicolumn{2}{|l|}{ Demographics } \\
\hline Age, years & $66.3 \pm 8.4$ \\
\hline Sex, male/female $(n)$ & $16 / 0$ \\
\hline $\mathrm{BMI}, \mathrm{kg} / \mathrm{m}^{2}$ & $24.7 \pm 4.2$ \\
\hline Race, (Caucasian/other) & $16 / 0$ \\
\hline \multicolumn{2}{|l|}{ Echocardiogram } \\
\hline LVEF, \% & $67.1 \pm 4.4$ \\
\hline $\mathrm{RV}$ diameter, mm & $22.2 \pm 3.4$ \\
\hline LVDD, normal/type I, n (\%) & I $(0.06) / 15(0.94)$ \\
\hline BNP, pg/mL & $17.3 \pm 18.7$ \\
\hline mMRC, I/2/3, n (\%) & $10(62.5) / 5(31.3) / /(6.3)$ \\
\hline Smoking, never/ex/current & $0 / 16 / 0$ \\
\hline pack-years & $48.0 \pm 26.9$ \\
\hline \multicolumn{2}{|l|}{ Lung function } \\
\hline Forced vital capacity, \% predicted & $92.6 \pm 21.1$ \\
\hline $\mathrm{FEV}_{1}, \%$ predicted & $53.9 \pm 19.7$ \\
\hline $\mathrm{FEV}_{\mathrm{I}}$ /forced vital capacity & $44.0 \pm 10.8$ \\
\hline Total lung capacity, \% predicted & $113.8 \pm 16.6$ \\
\hline Inspiratory capacity, \% predicted & $88.5 \pm 24.8$ \\
\hline IC/TLC & $0.36 \pm 0.09$ \\
\hline Residual volume, \% predicted & $164.6 \pm 40.3$ \\
\hline $\mathrm{RV} / \mathrm{TLC}$ & $0.48 \pm 0.08$ \\
\hline $\operatorname{Raw}\left(\mathrm{cmH}_{2} \mathrm{O} / \mathrm{L} / \mathrm{sec}\right)$ & $3.5 \pm 1.2$ \\
\hline $\mathrm{DL}_{\mathrm{co}}, \%$ predicted & $54.3 \pm 20.6^{\mathrm{a}}$ \\
\hline MIP $\left(\mathrm{cmH}_{2} \mathrm{O} / \%\right.$ predicted $)$ & $-92 \pm 32 / 92 \pm 30$ \\
\hline $\operatorname{MEP}\left(\mathrm{cmH}_{2} \mathrm{O} / \%\right.$ predicted $)$ & $126 \pm 30 / 1 \mid 2 \pm 24$ \\
\hline $\mathrm{PaO}_{2}, \mathrm{mmHg}$ & $70.2 \pm 6.3$ \\
\hline $\mathrm{PaCO}_{2}, \mathrm{mmHg}$ & $37.1 \pm 4.7$ \\
\hline $\mathrm{SO}_{2}, \%$ & $93 \pm 2$ \\
\hline \multicolumn{2}{|l|}{ Main comorbidities, n (\%) } \\
\hline Hypertension & $9(56.3)$ \\
\hline Type 2 diabetes & $3(18.8)$ \\
\hline Hypercholesterolemia & $5(3 \mid .3)$ \\
\hline Sleep apnea & $2(12.5)$ \\
\hline Chronic kidney disease & $13(8 \mid .3)$ \\
\hline Osteoporosis & $2(12.5)$ \\
\hline Chronic atrial fibrillation & I (6.3) \\
\hline CAD & $\mathrm{I}(6.3)$ \\
\hline Gastroesophageal reflux disease & I (6.3) \\
\hline Alcoholism, ex/current & $5(3 \mid .3) / 0$ \\
\hline \multicolumn{2}{|l|}{ Therapies, n (\%) } \\
\hline LABA & I (6.3) \\
\hline$L A B A+I C S$ & $5(3 \mid .3)$ \\
\hline LABA + ICS + LAMA & $9(56.3)$ \\
\hline LABA + LAMA & I (6.3) \\
\hline Beta-blockers & 0 \\
\hline ACE inhibitors & $6(37.5)$ \\
\hline Amlodipine & $5(31.3)$ \\
\hline
\end{tabular}

Table I (Continued)

\begin{tabular}{ll}
\hline Clinical data & COPD patients $(\mathbf{n}=\mathbf{I 6})$ \\
\hline Spironolactone & $\mathrm{I}(6.3)$ \\
Diltiazem & $\mathrm{I}(6.3)$ \\
Amiodarone & $\mathrm{I}(6.3)$ \\
Furosemide & $\mathrm{I}(6.3)$ \\
Hydrochlorothiazide & $6(37.5)$ \\
Aspirin & $2(12.5)$ \\
Statin & $5(31.3)$ \\
Metformin & $3(18.8)$ \\
Other hypoglycemics & $\mathrm{I}(6.3)$ \\
Warfarin & $\mathrm{I}(6.3)$ \\
\hline
\end{tabular}

Notes: Unless otherwise stated, data are presented as mean \pm SD. ${ }^{\text {a Thirteen }}$ patients were able to achieve acceptable test criteria for $\mathrm{DL}_{\mathrm{cO}}$.

Abbreviations: BMI, body mass index; COPD, chronic obstructive pulmonary disease; LVEF, left ventricular ejection fraction; RV, right ventricle; LVDD, left ventricular diastolic dysfunction; BNP, B-type natriuretic peptide; mMRC, modified Medical Research Council; FEV , forced expiratory volume in I second; IC/TLC, inspiratory capacity/total lung capacity ratio; Raw, airway resistance; $\mathrm{DL}_{\mathrm{co}}$, carbon monoxide diffusing capacity; MIP, maximal inspiratory pressure; MEP, maximal expiratory pressure; CAD, coronary arterial disease; LABA, long-acting beta2-agonist; ICS, inhaled corticosteroids; LAMA, long-acting anticholinergics; $\mathrm{ACE}$, angiotensin-converting-enzyme.

\section{Doppler echocardiography}

All individuals underwent comprehensive two-dimensional echocardiography using an IE33 (Philips, Andover, MA, USA) echocardiography system with a 2-5 $\mathrm{MHz}$ matrix transducer and tissue Doppler imaging software. Patients were studied in the left lateral decubitus position and always by the same physician. Quantification of the cardiac chambers was performed according to American Society of Echocardiography guidelines. ${ }^{28}$

\section{B-type natriuretic peptide}

Blood samples were obtained on day 1 and plasma B-type natriuretic peptide levels were measured by chemiluminescent enzyme immunoassay.

\section{Acquisition of RR interval}

The RR interval (RRi) was registered using the Polar $^{\circledR}$ system at rest in the supine (10 minutes), standing (10 minutes), and seated (10 minutes) positions, as well as during M-RSA (4 minutes, in the seated position). In this maneuver, the researchers instructed the subjects to perform a sequence of deep and slow inspirations and expirations, with lung volumes varying from the TLC to the RV. Each breathing cycle lasted 10 seconds ( 5 seconds of inspiration, 5 seconds of exhalation). The volunteers followed the researchers' verbal commands in order to maintain the respiratory rate of six breaths per minute, which is expected to induce the maximum respiratory sinus arrhythmia. ${ }^{10}$ An elastic belt (Polar T31 transmitter, Polar Electro, Kempele, Finland) was attached to the chest of each volunteer at the level of the lower third of the sternum. 
The belt contains a stable case with heart rate electrodes, an electronic processing unit, and an electromagnetic field transmitter. The heart rate signals are continuously transmitted to the Polar Advantage receiver unit via an electromagnetic field. ${ }^{29}$ All data were transferred to a computer using Polar Pro-Trainer $5 \mathrm{TM}^{\circledR}$ software.

\section{HRV analysis}

HRV was analyzed using Kubios $H_{R V}{ }^{\circledR}$ version 2.1 software (Matlab, Kuopio, Finland). The total period of RRi collection was scrutinized, and the most stable noise-independent segment (ie, without ectopic beats, arrhythmic events, missing data, and/or noise events) was selected for analysis. This interval contained at least 256 points. ${ }^{30}$ Time and frequency domains analysis and non-linear analysis were performed in the supine, seated, and standing positions and during M-RSA. The mean RRi, the standard deviation of the normal RR intervals (SDNN), and the square root of the mean squared differences of successive RR intervals (RMSSD) were obtained for time domain linear analysis. Low frequency (LF) and high frequency (HF), both expressed in normalized units (nu), included frequency domain HRV indices. In addition, the LF/HF ratio was calculated to verify the sympathovagal balance. ${ }^{30}$ Non-linear HRV analysis was performed from SD1 (standard deviation measuring the dispersion of points in the plot perpendicular to the line of identity), SD2 (standard deviation measuring the dispersion of points along the line of identity), alpha1 and alpha2 (respectively, short-term and long-term fluctuations of detrended fluctuation analysis), and approximate entropy (ApEn) indices. SD1 is related to parasympathetic activity, while SD2 reflects total variability. Alpha1 and alpha2 were used to quantify the fractal property of the temporal series of the RRi and, in healthy conditions, the alpha1 value should be close to 1 and higher than the alpha 2 value. ${ }^{31}$ In turn, ApEn detects changes in a time series and provides a non-negative number to the series. Higher values indicate more complex data. ${ }^{32}$

Moreover, in order to verify responses due to postural changes, HRV indices were also expressed in deltas $(\Delta)$ ( $\Delta$ supine-sitting is the HRV index in the supine position minus the HRV index in the seated position; $\Delta$ supine-M-RSA is the HRV index in the supine position minus the HRV index during M-RSA; and $\Delta$ sitting-M-RSA is the HRV index in the seated position minus HRV index during M-RSA).

\section{Statistical analysis}

The sample size for the current study was estimated considering correlation analyses between HRV indices and pulmonary function. To reach an $80 \%$ chance of detecting a moderate association $(r \geq 0.6)$ at an $\alpha$ level of 0.05 , the power calculation indicated a sample of 16 patients. ${ }^{33}$ The results are reported as the mean \pm standard deviation, and all statistical analysis was conducted at a 95\% level of significance. According to variable distribution, the KruskalWallis $H$ test, with the Mann-Whitney post hoc test, was performed to evaluate differences between deltas of HRV indices. Pearson's or Spearman's moment correlations coefficient was used to test the association between variables. The magnitude of correlations was determined considering the following classification scheme for $r$-values: $0.26-0.49$, low or weak; $0.50-0.69$, moderate; $0.70-0.89$, strong or high; and 0.90-1.0, very high. ${ }^{34}$ Backward linear regression analysis was performed to identify the independent predictor of impaired lung function in COPD patients. Statistical analysis was performed using Statistical Package for the Social Sciences version 17.0 software (SPSS Inc, Chicago, IL, USA).

\section{Results \\ General characteristics}

Twenty-six COPD patients from a specialized outpatient COPD clinic (convenience sample) at the Federal University of São Paulo were recruited. Ten patients did not fulfill the inclusion criteria (long-term oxygen therapy, $n=1$ ); recent decompensation episode $(n=4)$; current alcoholism $(n=1)$; participation in pulmonary rehabilitation $(n=1)$; and refusal to participate $(n=3)$. Baseline patient characteristics are shown in Table 1. All of the patients enrolled were ex-smokers (48.0 \pm 26.9 pack-years) and had normal left ventricular ejection fraction $(67.1 \% \pm 4.4 \%)$, without alterations in right ventricular diameter $(22.2 \pm 3.4 \mathrm{~mm})$. Most of patients $(94 \%)$ presented with left ventricular diastolic dysfunction type 1 (impaired relaxation) and mean plasma B-type natriuretic peptide levels of $17.3 \mathrm{pg} / \mathrm{mL}$. The majority of patients (62.5\%) presented with a modified Medical Research Council scale score of 1 and the main reported comorbidity was chronic kidney disease $(81.3 \%)$. With regards to medical treatment, most patients received combined respiratory therapy $(n=9)$.

\section{Lung function}

Three patients were not able to achieve acceptable test criteria for $\mathrm{DL}_{\mathrm{CO}}$. The mean $\mathrm{FEV}_{1}$ was $53.9 \% \pm 19.7 \%$, with a range encompassing Global Initiative for Chronic Obstructive Lung Disease stages II-IV. Subjects presented with a slight reduction in $\mathrm{DL}_{\mathrm{CO}}$ and increased airway resistance (Raw) with 
evidence of air trapping. All subjects presented with normal respiratory muscle force and normoxemia (Table 1).

\section{HRV indices during postural changes}

Comparison of HRV indices between supine-stand, supinesitting, and sitting-M-RSA maneuvers are shown in Figure 1. COPD patients presented with significant changes in time and frequency domain $(\triangle \mathrm{SDNN}, \Delta \mathrm{RMSSD}, \Delta \mathrm{LF} n u, \Delta \mathrm{HF} n \mathrm{nu})$ and non-linear $(\Delta \mathrm{SD} 1, \Delta \mathrm{SD} 2, \Delta$ alpha1, $\Delta$ alpha2, $\Delta \mathrm{ApEn})$ HRV indices, when responses due to postural changes were compared ( $\Delta$ supine-stand versus $\Delta$ sitting-M-RSA and $\Delta$ supine-sitting versus $\Delta$ sitting-M-RSA; $P<0.05$ ).

\section{Association between pulmonary function and HRV indices}

A number of moderate statistically significant associations between HRV indices $(\Delta)$ and variables from lung function tests are demonstrated in Figure 2. Both linear (HF nu) and non-linear (SD1, SD2, alpha1) deltas showed correlations with simple spirometry $\left(\mathrm{FEV}_{1}[\mathrm{~L}]\right), \mathrm{DL}_{\mathrm{CO}}(\%)$ and whole body plethysmography ( $\mathrm{Raw}\left[\mathrm{cmH}_{2} \mathrm{O} / \mathrm{L} / \mathrm{sec}\right], \mathrm{RV}[\%]$, IC/ TLC and RV/TLC ratio). Also, absolute linear values with $\mathrm{HRV}$ at rest (sitting) showed moderate statistically significant associations with lung function test variables ( $\mathrm{LF} / \mathrm{HF}$ ratio versus total gas volume [TGV] [\%], $r=0.53$; LF/HF ratio versus RV [\%], $r=0.52$; HF nu versus TGV [\%], $r=-0.53$; $P<0.05$; Figure 3 ). In addition, we observed significant correlations ranging from 0.50 to 0.59 between $\mathrm{FEV}_{1}(\mathrm{~L})$, SLV (RV [\%], TGV [\%], IC/TLC, and RV/TLC) and DL (\%) and linear (LF [msec], LF [nu], RMSSD [msec], LF/ $\mathrm{HF}$ ratio, HF [nu]) and non-linear (SD2, msec) HRV indices $(\Delta)$, which are not shown in Figures 2 and 3. Furthermore, linear regression analysis revealed that $\Delta \mathrm{RRi}$ supine-MRSA (msec) was independently related to $\mathrm{DL}_{\mathrm{CO}}(\%)$ in this COPD cohort $\left(\left[r=-0.77, r^{2}=0.43, P<0.05\right.\right.$, standard error of estimate $=16.3 ; \mathrm{DL}_{\mathrm{CO}}[\%]=60.55-[0.23 \Delta \mathrm{RRi}$ supineM-RSA]); (Figure 4).

\section{Discussion}

This is the first study to correlate non-linear HRV indices with SLV and $\mathrm{DL}_{\mathrm{CO}}$ in COPD patients. According to our main hypotheses, the primary findings of the present study were as follows: responses in HRV indices due to postural changes are more evidenced in transitions from supine or sitting positions to M-RSA; there are moderate associations between lung function impairments and poor heart rate dynamics; and there is a strong relationship between $\mathrm{DL}_{\mathrm{CO}}(\%)$ and $\mathrm{RRi}(\Delta)$ during the sitting-M-RSA transition (parasympathetic stimuli).

\section{Responses in HRV due to postural changes}

HRV provides important information on cardiac regulation, by means of indices that indicate normal responses to autonomic stimuli. ${ }^{35}$ The autonomic nervous system in patients with COPD appears to work at an overwhelmed level; therefore, autonomic control is saturated and its modulation to different stimuli is depressed. ${ }^{8}$ The same pattern of autonomic (dys)regulation has been found in patients with chronic respiratory failure (lung fibrosis and COPD) ${ }^{36}$ and asthma $^{37}$ during autonomic maneuvers.

Another interesting finding of the current study was that the respiratory maneuver (parasympathetic stimuli) seemed to cause more turbulence in autonomic nervous system function compared with sympathetic maneuvers (ie, during postural active maneuver), both for linear (Figure 1A-D) and non-linear (Figure 1E-I) HRV indices. In healthy humans, sympathetic activity appears to be influenced by the pattern of breathing (depth and initial pulmonary volume). ${ }^{11}$ Most of the subjects included in this study $(n=13)$ presented with signs of air trapping (augmented RV and RV/TLC ratio). Although markers of sympathetic activation were not measured in the present study, we speculate that the elevated starting volume and also high work of breathing could cause elevated sympathetic activation; therefore, autonomic cardiac control would be reset to a new level.

\section{Lung function impairment versus diminished heart rate dynamics}

Airflow obstruction increases the risk of cardiac injury in patients with moderate to severe COPD, ${ }^{38}$ and its association between pulmonary function and occurrence of ventricular arrhythmia has been previously shown. ${ }^{4}$ Our results showed moderate correlations between lung impairment and linear and non-linear HRV indices (Figures 3 and 4). Not only do these findings indicate that worse heart rate dynamics can be related to more severe airflow obstruction, but also that both simple spirometry and SLV should be used to express these interactions. In addition, detrended fluctuation analysis (obtained from alpha1 and alpha2 indices) and Poincaré plot analysis (obtained from SD1 and SD2 indices) add powerful information to the results hereby presented, as the former is not contaminated by changes in the external environment (such as respiration) $)^{39}$ and the latter can capture many types of variability in oscillations (as recurrence and periodicity) in a time series. ${ }^{40}$ Therefore, the present study has demonstrated that using both linear and non-linear HRV indices can provide detailed knowledge about cardiac autonomic dysfunction in 


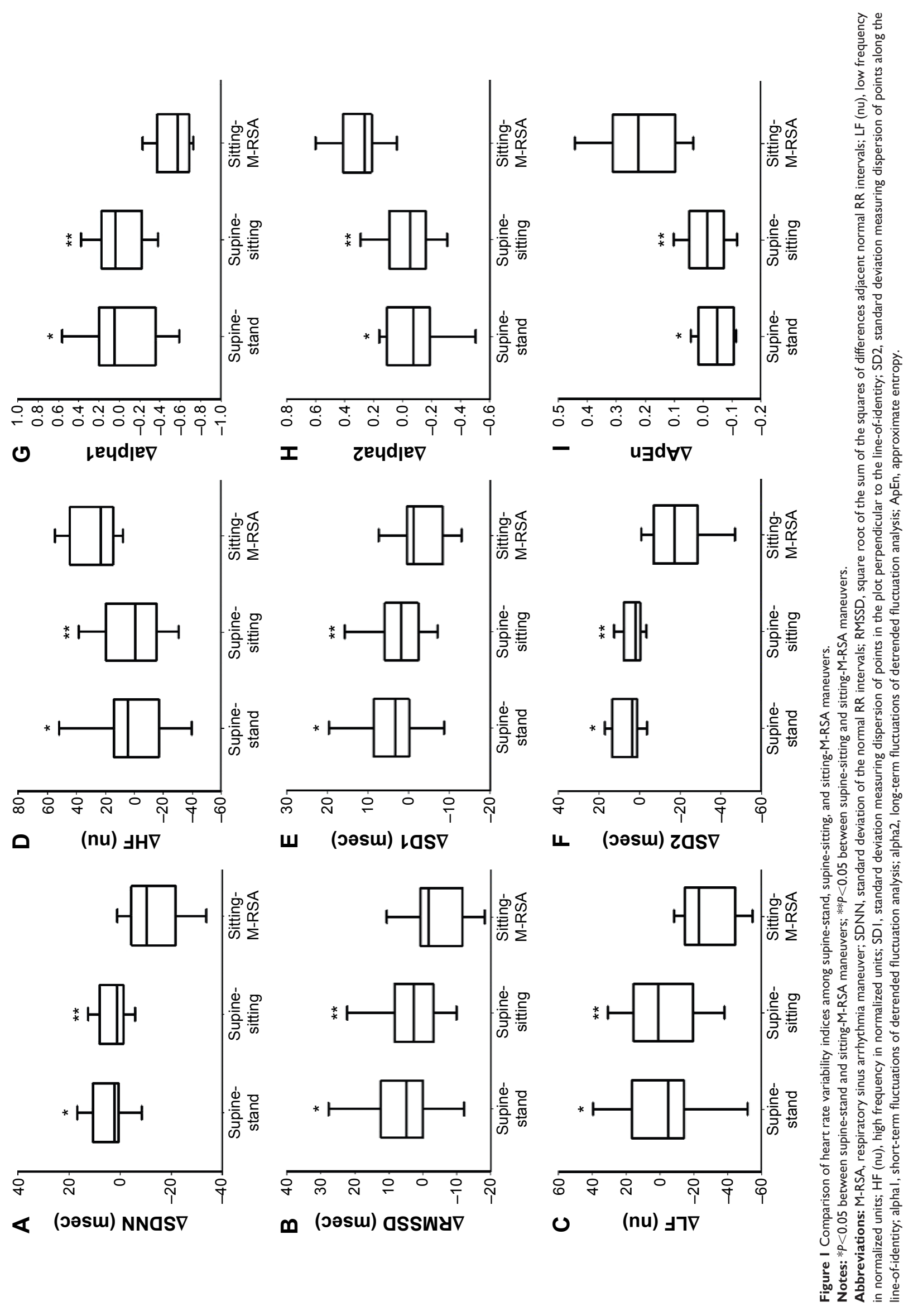



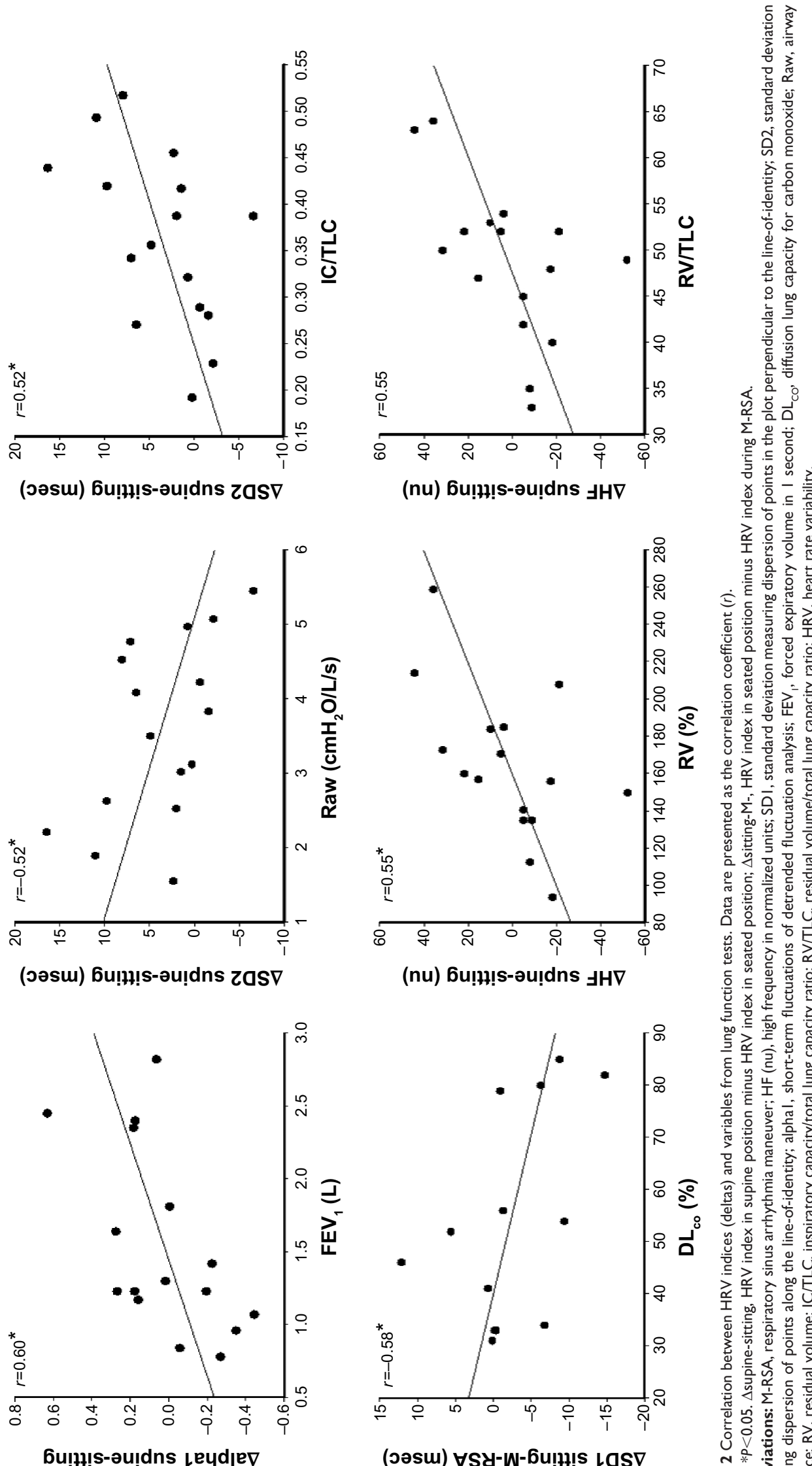

bu!ł!s-əu!dns Leydeק

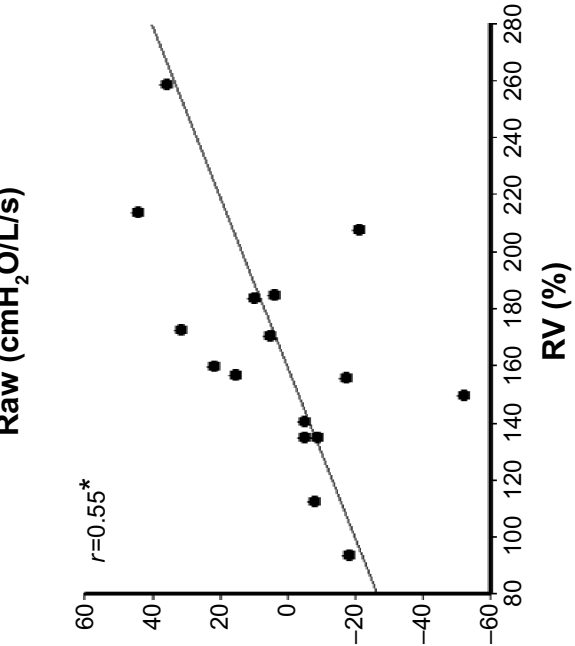

(nu) bu!n!s-əu!dns $\mathrm{H} \nabla$

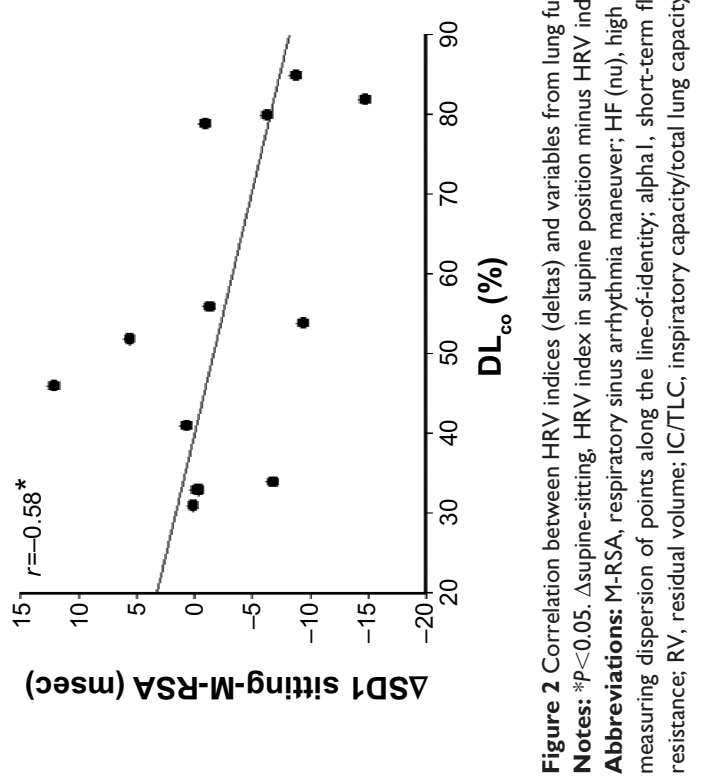



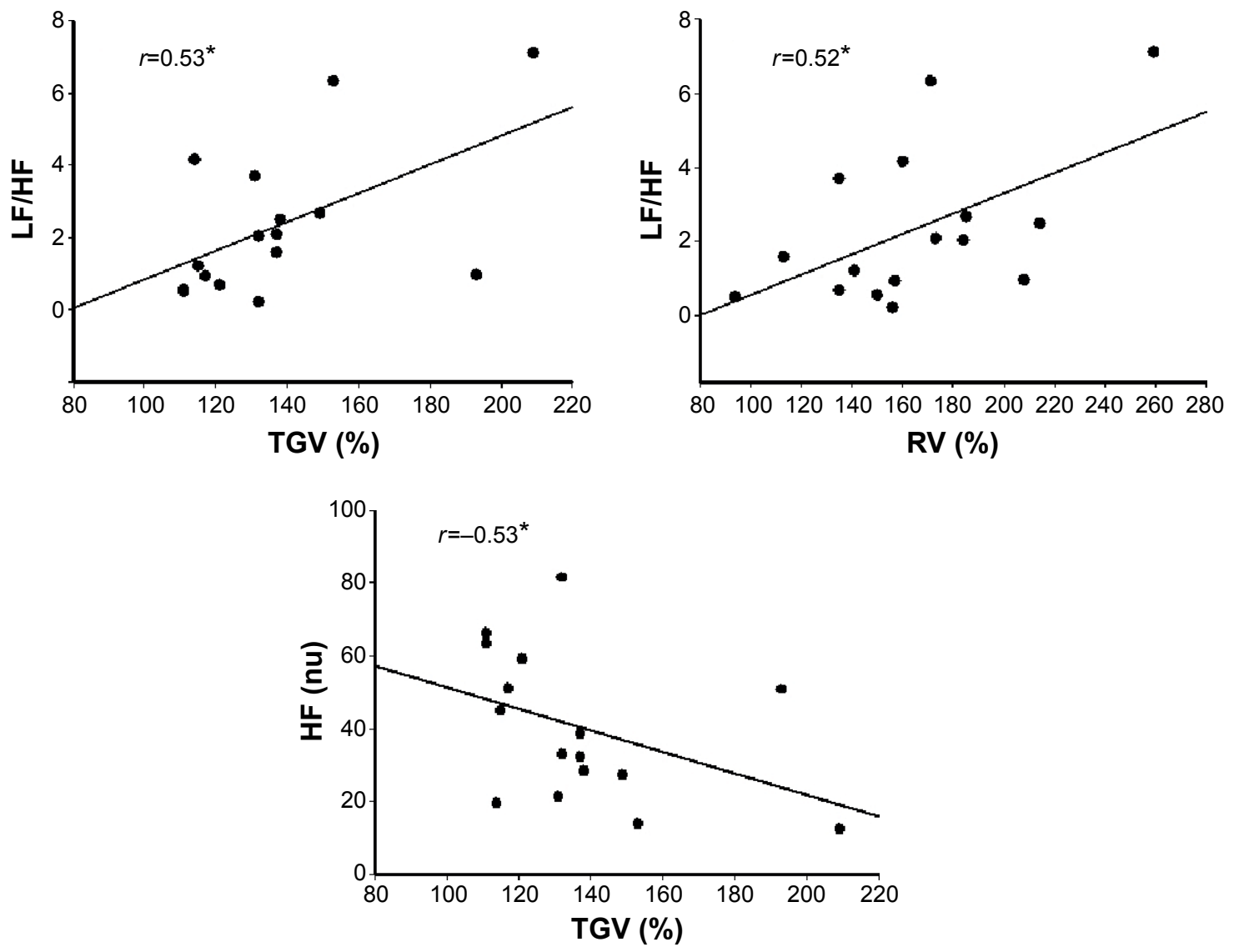

Figure 3 Correlation between heart rate variability indices (absolute values) and variables from lung function tests.

Note: $* P<0.05$.

Abbreviations: LF/HF, low frequency/high frequency ratio; HF (nu), high frequency in normalized units; TGV, total gas volume; RV, residual volume.

COPD patients and, indirectly, potentially estimate the risk of adverse cardiac events.

On the one hand, a recent study has suggested that poor HRV is not necessarily linked to increased COPD severity, estimated by $\mathrm{FEV}_{1}(\%) .{ }^{18}$ On the other hand, Corbo et al ${ }^{19}$ have supported an association between abnormal cardiac

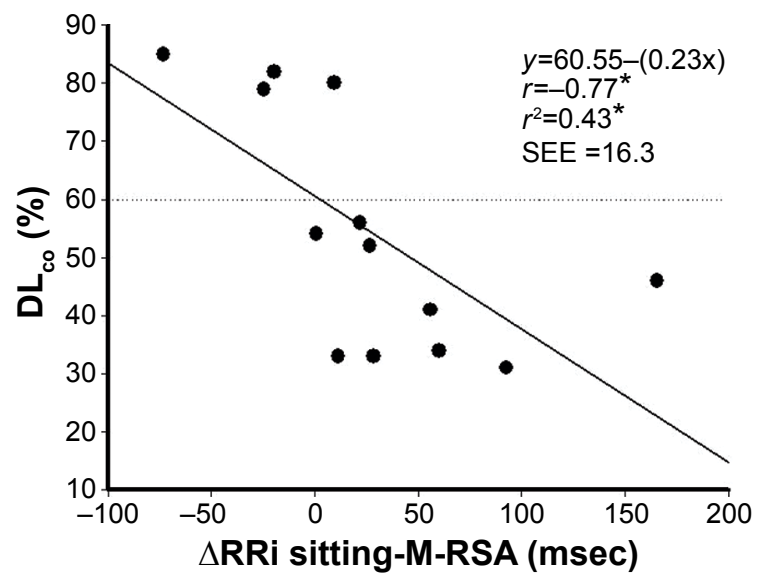

Figure 4 Backward linear regression.

Note: $* p<0.05$.

Abbreviations: $\mathrm{DL}_{\mathrm{co}}$, diffusion lung capacity for carbon monoxide; $\triangle \mathrm{RRi}$ sitting-MRSA, RRi in seated position minus RRi during M-RSA; SEE, standard error of estimate. autonomic regulation at rest and the IC/TLC ratio. The results presented here show that the values of pulmonary function variables indicating lung impairment (ie, $\mathrm{DL}_{\mathrm{CO}}<60 \%$, Raw $>2.5 \mathrm{cmH}_{2} \mathrm{O} / \mathrm{L} / \mathrm{sec}, \mathrm{RV}>140 \%, \mathrm{TGV}>130 \%, \mathrm{RV} /$ TLC $>0.4,{ }^{23-25} \mathrm{IC} / \mathrm{TLC}<0.28,{ }^{16}$ and $<0.25^{14}$ ) are moderately correlated with abnormal resting HRV indices (eg, high LF/HF ratio and low HF nu; Figure 3) and also with abnormal postural responses $(\Delta)$, as shown in Figure 2. Since COPD is a complex disorder with diverse pathophysiological manifestations, SLV and $\mathrm{DL}_{\mathrm{CO}}$ seem to accurately capture the wide variability in airways resistance, resting lung hyperinflation, and integrity of the alveolar-capillary interface.

\section{$D L_{C O}$ and its relationship with HRV- $\Delta R R i$ sitting-M-RSA}

A strong and negative relationship between $\mathrm{DL}_{\mathrm{CO}}$ and the $\mathrm{RRi}$ response to an autonomic maneuver (M-RSA) was found in the present study (Figure 4). The reasons why these two variables correlate cannot be fully elucidated and further investigation is required. However, some hypotheses can be considered. First, both reduced $\mathrm{DL}_{\mathrm{CO}}$ and an 
abnormal response to parasympathetic autonomic stimuli are independent expected markers of physiological impairment in COPD. Reis et $\mathrm{al}^{9}$ have recently demonstrated that COPD patients with diminished respiratory muscle strength also exhibit a reduction in vagal tone during an M-RSA. Aside from respiratory muscle weakness (one of the alveolar capillary membrane components), lung diffusion capacity may be changed by capillary blood volume factors. ${ }^{22}$ In this context, the role of sympathetic overactivation could contribute to the already reduced $\mathrm{DL}_{\mathrm{CO}}$, as far as it modifies pulmonary capillary tone and capillary blood filling.

In addition, in healthy aging, the RRi dynamic shows higher regularity and consistent loss of complexity, which leads to lower adaptability to physiological stress. ${ }^{41}$ In the presence of COPD, the respiratory modulation of RRi variability is even more reduced. ${ }^{8}$ Our results show that the greater the RRi imbalance in sitting-M-RSA transition (subjects with $\Delta>0$ ), the worse the $\mathrm{DL}_{\mathrm{CO}}$.

\section{Clinical implications}

The present study has potentially important clinical implications with respect to HRV analysis in COPD, which is a simple, low-cost method that provides not only information on cardiac autonomic function but also adverse outcomes, such as a heightened risk of sudden cardiac death. ${ }^{42}$ Moreover, nonlinear HRV analysis complements linear analysis since detrended fluctuation analysis (alpha1 and alpha 2 indices) is not contaminated by changes in the external environment ${ }^{39}$ and Poincaré plot analysis (SD1 and SD2 indices) can capture many types of variable oscillations, such as recurrence and periodicity, in a time series. ${ }^{40}$ As whole body plethysmography and $\mathrm{DL}_{\mathrm{CO}}$ are not widely available and costly, our results demonstrate that, by using a straightforward, readily applicable HRV analysis method in patients with moderate to severe COPD, we could infer that impaired autonomic adjustment is related to the severity of pulmonary disease. Thus, when whole body plethysmography and DLCO are not available, HRV analysis may be considered as an assessment approach in COPD.

\section{Limitations}

Naturally, the current study has some limitations. First, we were only able to include a small number of volunteers and they were all men. Hence, our study cannot infer conclusions regarding the relationship between impaired lung function and HRV indices in female COPD patients. However, the power calculation demonstrated that 16 subjects can achieve an $80 \%$ likelihood of detecting a moderate correlation at an $\alpha$ level of 0.05 . Second, we acknowledge that addition of a control group might have added useful comparative information to the current results. In addition, the term "sympathovagal balance" refers to a reciprocal relationship between HF and LF HRV components. ${ }^{43}$ Therefore, this measure provides insights into both high sympathetic modulation and reduced vagal tone. Clearly, the presence of comorbidities that cause sympathetic overactivation might impact our results, and this is another limitation of our study. Nevertheless, our sample describes a "real-life" COPD cohort being managed clinically where the presence of systemic inflammation seems to be shared between COPD and other comorbidities, such as hypertension, diabetes, and ischemic heart disease.$^{44-47}$ In this study, markers of sympathetic activation were not quantified, so the occurrence of sympathetic overactivation is hypothetical at this time. Finally, although HRV cannot measure autonomic nervous system activity, it is a noninvasive clinic tool that can be used to study neural cardiac regulation, which has been well established previously. ${ }^{48}$

\section{Conclusion}

In conclusion, our results show that, in patients with moderate to severe COPD, responses in HRV indices due to postural changes are more evident when they are subjected to a respiratory maneuver such as M-RSA. Moreover, a higher level of lung function impairment is related to poorer heart rate dynamics, the latter evidenced by both linear and nonlinear HRV analysis. Finally, there is a strong and negative relationship between $\mathrm{DL}_{\mathrm{CO}}(\%)$ and $\mathrm{RRi}$ during parasympathetic stimuli ( $\Delta$ sitting-M-RSA). Future investigation is needed to further elucidate the role of HRV analysis in patients with pulmonary disease.

\section{Acknowledgments}

The authors thank all their colleagues from the Pulmonary Function and Clinical Exercise Physiology Division for friendly collaboration. They also express their gratitude to all volunteers for their effort and cooperation throughout the study. Finally, they thank the National Research Council (CNPq-Brazil) and the São Paulo Research Foundation (FAPESP) (2015/06254-0) for financial support.

\section{Disclosure}

The authors report no conflicts of interest in this work.

\section{References}

1. O’Donnell DE, Laveneziana P, Neder JA. Lung function. Eur Respir Monogr. 2013;62:127-145.

2. Global Initiative for Chronic Obstructive Lung Disease (GOLD). Global strategy for the diagnosis, management and prevention of chronic obstructive pulmonary disease. 2014. Available from: www.goldcopd. org. Accessed 15 October, 2014. 
3. Jousilahti P, Vartiainen E, Tuomilehto J, Puska P. Symptoms of chronic bronchitis and the risk of coronary disease. Lancet. 1996;348: 567-572.

4. Engström G, Wollmer P, Hedblad B, Juul-Möller S, Valind S, Janzon L. Occurrence and prognostic significance of ventricular arrhythmia is related to pulmonary function. A study from "Men Born in 1914," Malmö, Sweden. Circulation. 2001;103:3086-3091.

5. Anthonisen NR, Connett JE, Enright PL, Manfreda J; Lung Health Study Research Group. Hospitalizations and mortality in the Lung Health Study. Am J Respir Crit Care Med. 2002;166:333-339.

6. Sin DD, Wu LL, Paul Man SF. The relationship between reduced lung function and cardiovascular mortality. A population-based study and a systematic review of the literature. Chest. 2005;127:1952-1959.

7. Volterrani M, Scalvini S, Mazzuero G, et al. Decreased heart rate variability in patients with chronic obstructive pulmonary disease. Chest. 1994;106:1432-1437.

8. Pagani M, Lucini D, Pizzinelli P, Sergi M, Mela GS, Malliani A. Effects of aging and of chronic obstructive pulmonary disease on RR interval variability. J Auton Nerv Syst. 1996;59:125-132.

9. Reis MS, Arena R, Deus AP, Simões RP, Catai AM, Borghi-Silva A. Deep breathing heart rate variability is associated with respiratory muscle weakness in patients with chronic obstructive pulmonary disease. Clinics. 2010;65:396-375.

10. Reis MS, Deus AP, Simões RP, Aniceto IA, Catai AM, Borghi-Silva A. Autonomic control of heart rate in patients with chronic cardiorespiratory disease and in healthy participants at rest and during a respiratory sinus arrhythmia maneuver. Rev Bras Fisioter. 2010;14:106-113.

11. Seals DR, Suwarno NO, Dempsey JA. Influence of lung volume on sympathetic nerve discharge in normal humans. Circ Res. 1990;67: $130-141$.

12. Andreas S, Anker SD, Scanlon PD, Somers VK. Neurohumoral activation as a link to systemic manifestations of chronic lung disease. Chest. 2005;128:3618-3624.

13. Criée CP, Sorichter S, Smith HJ, et al. Body plethysmography and its principles and clinical use. Respir Med. 2011;105:959-971.

14. Casanova C, Cote C, Torres JP, et al. Inspiratory-to-total lung capacity ratio predicts mortality in patients with chronic obstructive pulmonary disease. Am J Respir Crit Care Med. 2005;171:591-597.

15. Zaman M, Mahmood S, Altayeh A. Low inspiratory capacity to total lung capacity ratio is a risk factor for chronic obstructive pulmonary disease exacerbation. Am J Med Sci. 2010;339:411-414.

16. Albuquerque AL, Nery LE, Villaça DS, et al. Inspiratory fraction and exercise impairment in COPD patients GOLD stages II-III. Eur RespirJ. 2006;28:939-944.

17. Boutou AK, Shrikrishna D, Tanner RJ, et al. Lung function indices for predicting mortality in COPD. Eur Respir J. 2013;42:616-625.

18. Camillo CA, Pitta F, Possani HV, et al. Heart rate variability and disease characteristics in patients with COPD. Lung. 2008;186:393-401.

19. Corbo GM, Inchingolo R, Sgueglia GA, Lanza G, Valente S. C-reactive protein, lung hyperinflation and heart rate variability in chronic obstructive pulmonary disease - a pilot study. COPD. 2013;10:200-207.

20. Miller MR, Hankinson J, Brusasco V, et al. ATS/ERS Task Force. Standardisation of spirometry. Eur Respir J. 2005;526:319-338.

21. Wanger J, Clausen JL, Coates A, et al. Standardisation of the measurement of lung volumes. Eur Respir J. 2005;26:511-522.

22. Macintyre N, Crapo RO, Viegi G, et al. Standardisation of the singlebreath determination of carbon monoxide uptake in the lung. Eur Respir J. 2005;26:720-735.

23. Barreto SS. [Lung volumes]. J Pneumol. 2002;28 Suppl 3:S83-S94. Portuguese.

24. Pereira CAC, Viegas CA, Alves RF. [Carbon monoxide diffusing capacity]. J Pneumol. 2002;28 Suppl 3:S122-S138. Portuguese.

25. Pereira CAC, Moreira MAF. [Plethysmography - airway resistance]. J Pneumol. 2002;28 Suppl 3:S139-S150. Portuguese.

26. Neder JA, Andreoni S, Lerario MC, Nery LE. Reference values for lung function tests: II. Maximal respiratory pressures and voluntary ventilation. Braz J Med Biol Res. 1999;32:719-727.
27. Williams AJ. Assessing and interpreting arterial blood gases and acidbase balance. BMJ. 1998;317:1213-1216.

28. Lang RM, Badano LP, Tsang W, et al. EAE/ASE recommendations for image acquisition and display using three-dimensional echocardiography. J Am Soc Echocardiogr. 2012;25:3-46.

29. Radespiel-TrogerM, RauhR, MahlkeC, GottschalkT,Muck-Weymann M. Agreement of two different methods for measurement of heart rate variability. Clin Auton Res. 2003;13:99-102.

30. Camm A, Malik M, Bigger J, et al. Task Force of European Society of Cardiology and the North American Society of Pacing Electrophysiology. Heart rate variability: standards of measurement, physiological interpretation, and clinical use. Circulation. 1996;93:1043-1065.

31. Ferreira MT. Caracterização do comportamento caótico da variabilidade da frequência cardíaca (VFC) em jovens saudáveis. [Characterization of heart rate variability (HRV) chaotic behavior in healthy young people]. TEMA Tend Mat Appl Comput. 2010;11:141-151. Portuguese.

32. Tarvainen MP, Niskanen JP, Lipponen JA, Ranta-Aho PO, Karjalainen PA. Kubios HRV - heart rate variability analysis software. Comput Method Prog Biomed. 2014;113:210-220.

33. Browner WS, Cummings SR, Hulley SB. [Estimating sample size and statistical power: key points]. In: Hulley SB, Cummings SR, Browner WS, Grady D, Hearst N, Newman TB, editors. [Designing Clinical Research: An Epidemiologic Approach]. 2nd ed. Porto Alegre, Brazil: Artmed; 2003. Portuguese.

34. Munro BH. Statistical Methods for Health Care Research. 4th ed. Philadelphia, PA, USA: JB Lippincott; 2000.

35. Soares-Miranda L, Sattelmair J, Chaves P, et al. Physical activity and heart rate variability in older adults - the Cardiovascular Health Study. Circulation. 2014;129:2100-2110.

36. Heindl S, Lehnert M, Criée C, Hasenfuss G, Andreas A. Marked sympathetic activation in patients with chronic respiratory failure. Am J Respir Crit Care Med. 2001;164:597-601.

37. Garcia-Araújo AS, Di Lorenzo VAP, Labadessa IG, et al. Increased sympathetic modulation and decreased response of the heart rate variability in controlled asthma. J Asthma. 2014;31:1-8.

38. Sin DD, Paul Man SF. Why are patients with chronic obstructive pulmonary disease at increased risk of cardiovascular diseases? The potential role of systemic inflammation in chronic obstructive pulmonary disease. Circulation. 2003;107:1514-1519.

39. Mäkikallio TH, Huikuri HV, Mäkikallio A, et al. Prediction of sudden cardiac death by fractal analysis of heart rate variability in elderly subjects. J Am Coll Cardiol. 2001;37:1395-1402.

40. Fishman M, Jacono FJ, Park S, et al. A method for analyzing temporal patterns of variability of a time series from Poincaré plots. $J$ Appl Physiol. 2012;113:297-306.

41. Pikkujämsä SM, Mäkikallio TH, Sourander LB, et al. Cardiac interbeat interval dynamics from childhood to senescence. Comparison of conventional and new measures based on fractals and chaos theory. Circulation. 1999;100:393-399.

42. Algra A, Tijssen JG, Roelandt JR, Pool J, Lubsen J. Heart rate variability from 24-hour electrocardiography and the 2-year risk for sudden death. Circulation. 1993;88:180-185.

43. Malliani A, Pagani M, Lombardi F, Cerutti S. Cardiovascular neural regulation explored in the frequency domain. Circulation. 1991;84:482-492.

44. Barnes PJ, Celli BR. Systemic manifestations and comorbidities of COPD. Eur Respir J. 2009;33:1165-1185.

45. Corsonello A, Incalzi RA, Pistelli R, Pedone C, Bustacchini S, Lattanzio F. Comorbidities of chronic obstructive pulmonary disease. Curr Opin Pulm Med. 2011;17 Suppl 1:S21-S28.

46. Cavaillès A, Brinchault-Rabin G, Dixmier A, et al. Comorbidities of COPD. Eur Respir Rev. 2013;22:454-475.

47. Mannino DM, Thorn D, Swensen A, Holguin F. Prevalence and outcomes of diabetes, hypertension and cardiovascular disease in COPD. Eur Respir J. 2008;32:962-969.

48. Akselrod S, Gordon D, Ubel FA, Shannon DC, Berger AC, Cohen RJ. Power spectrum analysis of heart rate fluctuation: a quantitative probe of beat-to-beat cardiovascular control. Science. 1981;213:220-222. 
International Journal of COPD

\section{Publish your work in this journal}

The International Journal of COPD is an international, peer-reviewed journal of therapeutics and pharmacology focusing on concise rapid reporting of clinical studies and reviews in COPD. Special focus is given to the pathophysiological processes underlying the disease, intervention programs, patient focused education, and self management protocols.

This journal is indexed on PubMed Central, MedLine and CAS. The manuscript management system is completely online and includes a very quick and fair peer-review system, which is all easy to use. Visit http://www.dovepress.com/testimonials.php to read real quotes from published authors 